\title{
POLICY TRANSFERABILITY AND HYSTERESIS
}

\section{Daily and Weekly Hours in the FRG and the U.S.}

\author{
Daniel S. Hamermesh
}

\section{INTRODUCTION}

The increasing ease of international communications has raised interest in comparing policies, including labor-market policies, in different economies. ${ }^{1}$ While the comparisons may have some inherent intellectual interest, presumably their main purposes are to instruct policy-makers in the countries involved (and perhaps in other countries too) about porentially attractive innovations that have succeeded elsewhere and that merit importing. The ultimate goal is to broaden the menu of policy choices by providing information on the successes and failures of the alternatives in different countries.

Such comparisons are implicit in the deluge of Western economists who, beginning in the late 1980's, descendert on Eastern Europe and the former Soviet Union offering advice on economic restructuring. This was nor an example of mutual learning, of each country hoping to improve its array of policies, but rather one of policy export. Ideally the purpose was to discover the particular indigenous problems that might require tailoring the policies being exported to the countries that were supposed to be aided.

In this chapter I consider the potential of these exercises for generating successful policies in the labor market. I examine in general terms the conditions that might make one country's successful policy more or less successfully transferable elsewhere. The analysis models various generic policies to consider what might make an optimal policy choice in one labor market more or less attractive in another. Specific guidelines that can indicate when policy transfers are more likely to be successful are then developed.

To begin considering whether this fairly general set of considerations is useful beyond focusing our thoughts about labor-market policy, I examine and compare German and American policies that set restrictions on hours worked. This leads naturally to studying differences in hours of work between the two countries, and to the quite neglected area of variations in patterns of hours of work per day and per week. 


\section{CONDITIONS FOR THE TRANSFERABILITY OF POLICY}

I abstract here from several international differences that will obviously make policies that are optimal in one country suboptimal in another. I assume throughout that there is a well-defined social welfare function (SWF), or that policymakers have an explicit maximand, and that these functions or maximands are identical in each country. Clearly, if there are different maximands, optimal policies in the face of identical shocks or conditions will differ across countries. Obversely, if a country's maximand changes to approximate another's more closely, a policy is more likely to be transferred successfully. Similarly, different technologies or endowments, including the amount of innate talent embodied in the labor force, will also dictate that optimal policies will differ among labor markets even in the face of identical preferences.

Throughour I examine the optimal choices by one society along a particular dimension of policy after each in a series of shocks. This is equivalent to comparing optimal choices among otherwise identical countries that differ only in the nature of the past choices they have made and shocks they have faced. It enables me to isolate what generates differing optimal policies even when tastes and technologies are identical. Moreover, it highlights the factors (beyond the obvious differences in tastes and technology) that produce greater differences or similarities in optimal policies.

The general pattern of analysis considers the optimal policy choice, $P_{0}^{*}$, before a first shock to the labor market occurs, the choice $P_{j}^{*}$ after it occurs, and where necessary the policy $P_{2}^{*}$ after it disappears. In each of the examples below I explore how the choices made in response to the first shock condition the choice of subsequent policies, thus presenting the nature of the hysteresis in the economy.

It should be clear that optinal policies do not differ because of any legislative, political or bureaucratic rigidity. There are no costs of adjusting policy in these models: Policies are changed immediately in response to current conditions and the shock. All the results hold in long-run equilibrium, i.e., international differences in optimal labor-market policies are long-run differences.

The specific models examined below have the same general properties, and the processes that generate the sequence $\left(P_{0}^{*}, P_{1}^{*}, P_{2}^{*}\right)$ are the same. These are:

$1 P_{0}^{*}$ is chosen given the SWF, the initial technology and the initial endowments of labor, skill, and other inputs.

2 As a result of this choice, skills and the returns to skill and raw labor change.

3 After this change a productivity shock occurs, essentially changing the nature of production.

4 In the face of this shock a new policy, $P_{1}^{*}$, becomes optimal and is implemented.

5 As a result of this new shock and of the particular choice $P_{1}^{*}$, skills and the returns to skill and raw labor change again.

6 The productivity shock disappears.

7 In light of its disappearance a new optimal policy, $P_{2}^{*}$, is chosen, $P_{2}^{*} \neq P_{0}^{*}$. The new policy differs from $P_{0}^{*}$ because the choice $P_{1}^{*}$ altered the underlying set of endowments and returns. 


\section{Two Examples Without Externalities}

In this subsection I examine two particular labor-market policies that produce no labor-market externalities. Consider first an effective minimum wage $w_{m}$ below which no one will be employed. The policy is chosen because society believes it is unfair for anyone to work below this wage and legislates its desires. ${ }^{2}$ I assume the policy has no impact on the productivity of other workers. Its only effect is to disemploy those whose productivity is below $w_{m}$, as in Meyer and Wise (1983). The SWF in this case is:

$$
S W F=Z\left(w_{m}\right) \prod_{i \in w>w_{m}} U\left(w_{i}\right) \quad \prod_{i \in w<w_{m}} U(0)
$$

where I assume that workers with productivity below the minimum receive an income at some base amount set for convenience at zero, and that $Z^{\prime}, U^{\prime}>0, Z^{\prime \prime}, U^{\prime \prime}<0$.

The SWF in (1) is maximized at the start of Period 0 when society chooses $w_{m 0}$ such that:

$$
\frac{Z^{\prime}}{Z}=\frac{U\left(w_{m 0}\right)-U(0)}{\prod U(w) \prod U(0)}
$$

where I now denote the two parts of the SWF without the subscripts. Society chooses a minimum wage $w_{m 0}$ to balance the gain from avoiding having anyone paid below the minimum against the loss in social welfare of having some workers displaced from their jobs and their earnings reduced to zero.

Let the distribution of productivity at the start of Period 0 be uniform on the interval $\left[w_{0}-a_{0} / 2, w_{0}+a_{0} / 2\right]$. Then any worker whose productivity is below $w_{m 0}$ receives zero earnings, so that a fraction $\left[w_{m 0}-w_{0}+a_{0} / 2\right] / a_{0}$ of the labor force is not working. During the period of nonwork from the start to the end of Period 0 , the productivity of nonemployed workers deteriorates at the rate $\delta .^{3}$ At the end of Period 0 the wage distribution for this segment of the population is thus shifted left by $\delta$ percent.

At the start of Period 1 the economy experiences a shock that shifts the distribution of productivity of the remaining employed workers to:

$$
w-f(w)=1 / a_{1}<1 / a_{0}, w_{\mathrm{m} 0}<w<w_{0}+a_{1} / 2
$$

The shock could, for examples, be a skill-using technical change, or a sudden additional accumulation of physical capital that is q-complementary with skill. Whatever the cause, it is exactly the kind of shock that is consistent with the widely noted increase in the dispersion of earnings in the United States during the 1980's (e.g., Bound and Johnson 1992). In the face of this shock a new minimum wage is chosen to maximize (1). With the increase in the average wage of those workers who 


\section{POLICY TRANSFERABILITY AND HYSTERESIS}

remained employed after the initial policy $w_{\mathrm{mo}}$ was imposed, the policy that maximizes (1) after the shock becomes $w_{m 1}>w_{m 0}$.

The new higher minimum causes some additional workers (those for whom $\left.w_{m 1}>w>w_{m 0}\right)$ to lose their jobs. Their productivity and that of workers whose productivity at $t=0$ was below $w_{m 0}$ depreciate at a rate $\delta$ during Period 1 . At the end of Period 1 one group of nonemployed workers has productivity on the domain $\left[\left(w_{0}-a_{0} / 2\right)(1-\delta)^{2}, w_{m 0}(1-\delta)^{2}\right]$, another on the domain $\left[w_{m 0}(1-\delta)\right.$, $\left.w_{m 1}(1-\delta)\right]$, and employed workers have productivity ranging from $w_{m 1}$ to $w_{0}+a_{1} / 2$.

At the start of Period 2 the shock that stretched the distribution of productivity to the right disappears, and the upper bound on productivity reverts to $w_{0}+a_{0} / 2$. The minimum wage that maximizes (1) is, however, no longer $w_{m 0}$. The depreciation of the skills of those who were disemployed by the previous minimum wage policies, $\mathrm{w}_{m 0}$ and $w_{m 1}$, has changed the distribution of productivity from what it was at the start of both Periods 0 and 1 . Even though the wages of employed workers have not changed since the start of Period 0 , the deterioration of human capital leads to a new optimum minimum wage policy, $w_{m 2}$, that differs from $w_{m 0}$. In particular, the shapes of $Z$ and $U$ ensure that $w_{m 1}>w_{m 2} \neq w_{m 0}{ }^{4}$ The failure of the optimal minimum to revert to its initial value stems solely from the bysteresis that is induced by the policy itself. Were costs of adjusting the policy instrument added to the model only the time paths, not the equilibrium optimal policies, would differ from those presented here.

The difference between $w_{m 0}$ and $w_{m 2}$ is within one country. But comparing two countries in which the distributions of wages of currently employed workers appear identical, the discussion shows that we cannot transfer a policy from Country 0 to Country 2 on the basis of these distributions. Transferability is only possible if we know the entire history of the distributions of wages in the two countries or have a complete inventory of the skills of both populations and know how those skills combine to generate output and wages. Simply pointing to identical distributions of wages of current labor-force members is not sufficient to justify claiming that the policy in Country 0 is appropriate for Country 2, even with identical social welfare functions and other current indicators.

I have demonstrated the role of policy hysteresis in labor demand in the context of a minimum-wage policy. The model could be applied mutatis mutandis to its close cousin, the overtime premium. If instead we base the assumption about the depreciation of human capital on total worker-hours, the results follow through. The policy sequence could be a 50-percent premium for overtime hours after $H^{*}$ hours per week; a shock that causes society to change standard hours to only $H^{*}-K$; and, after the shock disappears, a new policy with standard hours part way between $H^{*}$ and $H^{*}-K$. From an initial equilibrium the changed policy leads employers to reduce total worker-hours (labor-demand is at least somewhat elastic), which leads to the depreciation of human capital as total worker-hours employed drop. This depreciation leads to a different equilibrium after the shock disappears.

Similar hysteresis, and similarly nontransferable policies, can arise from workers' decisions about labor supply in models of taxes and transfers rather than the employers' decisions that underlay the hysteresis in the previous model. Consider a 
balanced-budget policy that offers all workers a guaranteed income of $T$ and finances it by a flat-rate tax on earnings at rate $t$. I assume hours per period are the same for all workers, that each person has the same reservation wage $w^{\circ}(T)$, $w{ }^{11}>0$, and that the $i^{\prime}$ th person will remain in the work force if net earnings exceed the reservation wage, i.e., if $(1-t) w_{\mathrm{i}}>w^{\circ}(T)$. Then given the distribution of wages, $w_{i}-f(w)$, society's goal is to maximize the SWF:

$$
S W F=\prod_{i \in(1-t) w>w^{*}(T)} U\left([1-t] w_{i}+T\right) \cdot \prod_{i \in(1-t) w_{<}<w^{*}(T)} U(T),
$$

subject to the balanced-budget condition for taxes and transfers:

$$
\Sigma T\{\text { all } \mathrm{i}\}=\Sigma t w_{i}\left\{i \in[1-t] w_{i}>w^{*}(T)\right\}^{5}
$$

At the start of Period 0 society chooses an optimal transfer $T_{0}$ and the tax rate $t_{0}$ that is dictated by the balanced-budget requirement in the face of the labor-force withdrawal induced by the income and substitution effects created by this policy. The skills of the fraction of the population that is induced to leave the labor force by the choices of $T_{0}$ and $t_{0}$ deteriorate during Period 0 .

A shock occurs at the start of Period 1 that alters the $w^{*}(T)$ at a given $T$, for example, an exogenous change in the number of young children at home. This leads to a new tax/transfer policy described by the set $\left(T_{1}, t_{1}\right)$. After the shock disappears and the function $w^{*}(T)$ shifts back to its original form, the change in the distribution of wages/productivity that had resulted from the deterioration of the skills of those who left the work force leads to a new policy, $\left(T_{2}, t_{2}\right)$, that differs from $\left(T_{0}\right.$, $t_{0}$ ). The same result would be produced if we assumed that the shock were, as before, a temporary change in the distributions of wages/productivity. Also as before, the discussion suggests that knowledge of wage distributions at one point in time is insufficient to justify transferring policies between countries.

\section{An Example With an Externality}

A somewhat different reason for the nontransferability of policy arises from hysteresis in the generation of externalities. Externalities induced by the accumulation of human capital guarantee that the optimal choice of policies that affect human capital cannot be based simply on current conditions, and cannot merely compare current conditions among economies. Consider an economy where production is carried on using two types of labor, $L_{1}$ and $L_{2}$ (the capital stock is ignored). There are no births and deaths, so that:

$$
\overline{L_{s}}=L_{1 t}+L_{2 t} \text {. }
$$

$L_{1}$ are skilled workers, who must be retrained at the start of each period. Even though it is not directly effective in production after the period when it is given, for 


\section{POLICY TRANSFERABILITY AND HYSTERESIS}

$N$ periods thereafter the training does increase efficiency. It can thus be thought of as engineering skills that make workers more productive immediately and that also enhance society's stock of general knowledge.

In each period the productivity of trained workers is augmented or reduced by a random shock $\theta$, where:

$$
\operatorname{Pr}\left\{\theta_{t}=\theta\right\}=\operatorname{Pr}\left\{\theta_{\mathrm{r}}=-\theta\right\}=0.5 .
$$

Accounting for all these features, output in period $t$ is:

$$
Y_{t}=H\left(L_{1 \imath}, \ldots, L_{1, t-N}\right) F\left(L_{1 t}\left[1+\theta_{t}\right], L_{2 t}\right) \text {, }
$$

where $H$ denotes the effective stock of durable knowledge, and $F$ is a two-factor production function with the standard properties, with $F_{1}>F_{2}$ if $L_{1}=L_{2}$ at the mean of $\theta(\theta=0) .{ }^{6}$ For simplicity let:

$$
H_{i}=\sum_{i=0}^{N} L_{1, t-i} .
$$

Consider a myopic training policy that maximizes $Y_{t}$ but ignores the $N$-period impact (the externalities generated by training). A farsighted policy would maximize the discounted stream of expected output, would enhance welfare, but would not imply anything different about the hysteresis in the choice of policy. ${ }^{7}$ The optimal myopic policy chooses $L_{1}^{*}$ such that:

$$
\frac{1}{H_{t}}=\frac{F_{1}\left[1+\theta_{t}\right]-F_{2}}{F} \text {. }
$$

The optimal policy trains the marginal worker so that the value of the training (in terms of output) through direct production and the impact on the stock of knowledge is equal to the reduction in output when the worker is shifted out of the unskilled work force.

At $t+1$ a new shock to skilled workers' productivity occurs, $\theta_{t+1}$, leading to a new optimum for the skilled work force, $L_{1, t+1}^{*}$. Even if $\boldsymbol{\theta}_{t+1}=\theta_{t}, L_{1, t+1}^{*} \neq L_{\mathrm{i}}^{*}$, unless $\theta_{t+1}=\theta_{t-N}$. In this simple specification the optimal policy will change with probability .5 even if the shock remains unchanged. ${ }^{8}$ The optimal policy will differ at $t+1$ because the history of productivity shocks produces a different set of externalities at time $t+1$ than existed at $t$.

Were we comparing two economies (labor markets) $J$ and $K$ at a point in time using this simple model, the optimal training policies would differ unless:

$$
\sum_{i=0}^{N} \theta_{J, t-i}=\sum_{i=0}^{N} \theta_{K, t-i} .
$$


The existence of externalities that arise from training requires different training policies in countries that appear identical in terms of the nature of production and the recent shocks that have affected the labor market. As in the other examples the knowledge required to transfer policies optimally exceeds what one might have thought is needed, and far exceeds the information that is likely to be available to the policy-maker.

\section{Positive Implications}

Since it deals with optimal policy, this discussion would appear to have only normative consequences. I believe it has positive implications too. Just as one can use price theory to study phenomena that appear to result from alleged cultural differences (Becker and Stigler 1977), this analysis tells us about the conditions under which we can expect imported policies to achieve their stated goals. In particular, it implies that an optimal policy will be transferred with greater success:

1 the more similar have been the patterns of shocks to the two labor markets; and

2 the more similar their past policy choices have been.

The comparison obviously depends on the term "similar," which requires specificity to be useful. In the case of shocks-to productivity or to the distribution of wages-greater similarity means that the time paths of the shocks to the two labor markets have exhibited greater cross-correlation. If policy choices have been made optimally, nothing more needs to be considered, since the similarity of past policies has resulted from the similarity of past shocks. If not, past departures from optimality in the country whose policy is exported ensure that the policy will be suboptimal in the importing country, other things equal. Obviously, importing failed policies makes litrle sense.

The general point here is in some ways qualitatively similar to the analysis of appropriate technology in the literature on economic development (e.g., Pack 1988). In that discussion factor endowments that differ across economies imply different optimal technologies. As such, the discussion rested on static models in which policy was exogenous. The issue here is dynamic, though, in that the analysis demonstrates that even when two economies appear to be currently identical one country's policy will be inappropriate for the other to the extent that their histories differ. This point is also somewhat similar to the discussion of European unemployment and the role of hysteresis in affecting current macroeconomic outcomes (e.g., Blanchard and Summers 1986; Franz 1987). It differs from that too, for here the differing histories have themselves resulted from different past choices about policies, so that today's optimal policy depends on the dynamic effects of past policy choices.

\section{HOURS LAWS: UNITED STATES AND THE FEDERAL REPUBLIC OF GERMANY}

In the remainder of this study I examine weekly hours and days of work in the Federal Republic of Germany (FRG hereafter) and the U.S. The different outcomes are instructive because: 
1 They show how two economies at roughly the same average wage level can have sharply different patterns of hours and days that have changed over time in different ways;

2 They indicate how little we know about daily and weekly work schedules at a time when rapid changes in patterns of labor-force participation may be generating changes in consumers' demands for retail and other firms' schedules; and

3 They may themselves result from differences in policies between the two countries.

Consider first the policies that might affect the mix of hours and days. Hours laws can be very specific (e.g., limits on weekly hours of teenage strawberry pickers in Oregon) or quite general (e.g., general limits on weekly hours). For the purposes of this chapter I restrict the discussion to the general cases of limits on hours per week or per day, as in the example outlined on pages 79-80. The basic law on hours in the United States has been remarkably unchanged since the passage of the Fair Labor Standards Act of 1938 . Workers must be paid a 50 percent premium over their regular hourly pay (including premiums for shift work, incentive pay, etc.) on all hours in excess of 40 per week, though in some cases (mainly governmental subunits) compensatory time can be provided in lieu of overtime pay. Note that there is no daily limit on hours beyond which the overtime premium must be applied in the U.S.

The situation is different in the FRG. For adults long-standing legislation limits the regular workday to 10 hours in a workweek limited to 48 hours. ${ }^{.}$The legislative constraint is hardly relevant, as collective and other agreements limit the normal workday to 8 hours. Note that in the FRG there are constraints on both daily and weekly hours.

Any differences in outcomes may in some ways illustrate the policy hysteresis outlined in the previous section. In particular, they could reflect the results of differences in the histories of policies regulating hours of work in the two countries. The extent to which this hysteresis is responsible is not known and is not the subject of this chapter. What we do know is that simply moving to identical policies in the two countries would not generate outcomes that are independent of their predecessor policies.

\section{WEEKLY AND DAILY HOURS IN THE FRG AND THE U.S.}

There have been numerous studies of differences in working time among industrialized countries, including the U.S. and the FRG, and of changes in work hours over time (e.g., Blyton 1985; Owen 1989). More technical studies have examined employers' demand for workers and hours in the context of the formal structure of production (see pages 90-92). There has been no formal examination of substitution by employers among additional workers, hours per week, and hours per day, or by workers among additional weeks per year, hours per 
week, and hours per day. The reason is very simple: Nearly all of our labor-force surveys, the main source of the underlying information, ask questions about weekly hours, so that information on this third margin of choice is rarely available.

As background I consider here the available evidence on differences and changes in weekly and daily hours in the U.S. and the FRG. Figure 4.1 graphs the cumulative distribution of workers by weekly hours actually worked in the two countries for 1970 and 1990 (1989 in the FRG). Two series are presented for the FRG in 1989, the first the standard German data, the second from the European Labor Force Survey in which the questions resemble those in the American Current Population Survey more closely. The figure begins at 30 hours per week because there are only tiny differences in the distributions below 30 hours. Several facts stand out from the figure:

- In 1970 average weekly hours were longer in the FRG than in the U.S. This had reversed by 1990 .

- In 1970 a greater fraction of German than of American workers had short workweeks. Also, a greater fraction of German workers had long ( $\geq 45$ hour) workweeks. In 1990 the opposite was true of both short and long workweeks.

- Except for a slight increase in the variance of weekly hours there was little change in the distribution of hours in the U.S. over these two decades. Changes in the FRG were much more substantial, with a large drop in the average and variance of weekly hours.
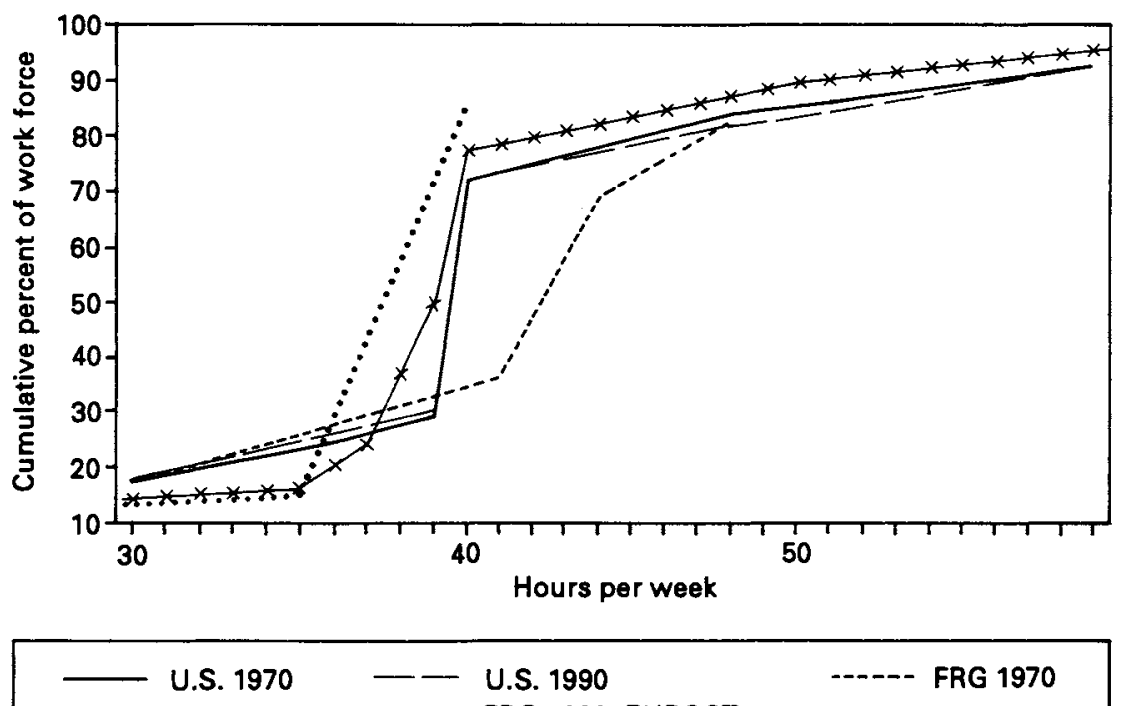

Figure 4.1 Hours per week-U.S. (1970, 1990); FRG $(1970,1989)$ 


\section{POLICY TRANSFERABILITY AND HYSTERESIS}

This information is fairly well known to students of labor markets in the two countries. Much less known are the data on days per week in conjunction with weekly hours worked.

There are no published data on the hours/days distinction for the United States. One can, however, use the 1977 Quality of Employment Survey to generate tabulations for the U.S. on usual weekly hours and usual days worked per week. Respondents were asked to check each day that they usually worked, and were asked, "The 'forty-hour week' is a very common term. ... During the average week how many hours do you work, not counting the time you take off for meals?" I believe this question elicits information on usual hours, but that its design reduces the concentration of responses at 40 hours per week.

A very similar table can be created for Germany using the 1990 wave of the German Socio-Economic Panel (GSOEP). The data on weekly hours are the response to the question, "How many hours on average is your actual work time [per week] including overtime?" Days are the response to the question, "How many days per week do you usually work?" [Author's translations.]

Tabulations from the American survey are shown in Table 4.1, while the German results are in Table 4.2. As in the data on actual weekly hours

Table 4.1 Usual Hours and Days, United States, 1977 (\% Distribution)

\begin{tabular}{lccc}
\hline & All Workers $^{\mathrm{a}}$ & $\begin{array}{c}\text { Salaried } \\
\text { Workers }^{\mathrm{b}}\end{array}$ & $\begin{array}{c}\text { Hourly Paid } \\
\text { Workers }^{\mathrm{c}}\end{array}$ \\
\hline $\begin{array}{l}\text { Weekly Hours } \\
\text { 10-20 }\end{array}$ & & & \\
$20.1-30$ & 2.5 & 1.4 & 3.8 \\
$30.1-35$ & 7.1 & 5.1 & 8.8 \\
$35.1-39$ & 8.7 & 9.3 & 8.0 \\
$39.1-40$ & 9.6 & 12.6 & 7.2 \\
$40.1-44$ & 32.2 & 27.4 & 38.0 \\
$44.1-47$ & 8.3 & 6.9 & 10.0 \\
$47.1-54$ & 7.8 & 10.7 & 5.0 \\
$54.1-69$ & 13.0 & 14.4 & 10.7 \\
$>69$ & 9.0 & 10.1 & 7.6 \\
Days & 1.9 & 2.2 & 1.0 \\
1 & & & \\
2 & 0.0 & 0.0 & 0.0 \\
3 & 0.5 & 0.4 & 0.6 \\
4 & 1.6 & 1.2 & 1.5 \\
5 & 2.2 & 1.4 & 2.9 \\
$6-7$ & 81.0 & 86.2 & 77.5 \\
\hline
\end{tabular}

Source Calculated from the Quality of Employment Survey, 1977

Notes:

i $\mathrm{N}=1,097$

${ }^{b} \mathrm{~N}=507$

' $\mathrm{N}=524$ 
DANIEL S. HAMERMESH

Table 4.2 Usual Hours and Days, FRG 1990, (\% Distribution)

\begin{tabular}{lccc}
\hline & All Workers $^{2}$ & $\begin{array}{c}\text { Salaried } \\
\text { Workers }^{\mathbf{b}}\end{array}$ & $\begin{array}{c}\text { Hourly Paid } \\
\text { Workers }^{c}\end{array}$ \\
\hline Hours & & & \\
$10-20$ & 6.2 & 8.8 & 5.6 \\
$20.1-30$ & 5.6 & 7.6 & 3.9 \\
$30.1-35$ & 1.9 & 2.1 & 1.8 \\
$35.1-39$ & 32.7 & 13.4 & 36.7 \\
$39.1-40$ & 22.2 & 34.7 & 26.0 \\
$40.1-44$ & 11.7 & 10.1 & 9.2 \\
$44.1-47$ & 8.4 & 8.0 & 7.4 \\
$47.1-54$ & 7.3 & 10.9 & 5.7 \\
$54.1-69$ & 3.2 & 3.5 & 2.8 \\
$>69$ & 0.8 & 0.9 & 0.9 \\
Days & & & \\
1 & 0.1 & 0.1 & 0.0 \\
2 & 0.7 & 0.9 & 0.6 \\
3 & 1.3 & 2.2 & 0.3 \\
4 & 1.4 & 1.7 & 0.6 \\
5 & 86.3 & 83.2 & 89.5 \\
$6-7$ & 10.2 & 11.9 & 9.0 \\
\hline
\end{tabular}

Source Calculated from the 1990 Wave (7) of the German Socioeconomic Panel, produced by the Deutsches Institut für Wirtschaftsforschung

Notes.

* $\mathrm{N}=4,525$

${ }^{\mathrm{b}} \mathrm{N}=1,978$

${ }^{\circ} \mathrm{N}=2,236$

presented in the figure, these data show that higher percentages of American workers have usual workweeks of less than 35 hours, or more than 47 hours, than do their German counterparts. The distributions of days also differ, at least in these samples: More Americans usually work fewer than 5 days, or more than 5 days, than do German workers. There is more dispersion in both weekly hours and days per week in the American labor force. This difference may be another reflection of the much discussed (and infrequently directly demonstrated) greater flexibility of the American labor market than its European counterparts.

There are two quite striking and hitherto unnoticed differences in work time between the two countries. In the U.S. salaried workers are more likely than hourly paid workers to be working exactly five days per week. In the FRG the opposite is the case. There is also an interesting difference in the length of the workweek by type of worker. In the U.S. salaried workers are more likely to be working long weeks than are hourly paid workers, but less likely to be working short weeks. In Germany they are more likely to be working long weeks or short weeks-there is much more dispersion in their weekly schedules, both regarding days and weekly 


\section{POLICY TRANSFERABILITY AND HYSTERESIS}

hours. Any explanation of these differences is obviously just speculation; but one sensible story is that the much greater extent and strength of German (blue-collar) unionism leads to much greater standardization of work schedules among hourly paid workers than in the U.S.

Cross-tabulations of weekly hours and days per week from the QES data are presented in Table 4.3, both in total and separately for salaried and hourly paid workers. " Unsurprisingly, long workweeks in terms of hours are associated with long workweeks in terms of days. There are, though, some workers (2.8 percent of the total) who put in no more than 40 hours per week but who work 6 or 7 days; and 0.4 percent of the total work more than 40 hours, bur fewer than 5 days per week.

Similar tabulations can be made (on the larger samples) from the 1990 wave of the GSOEP. These are presented in Table 4.4 in exactly the same format as the

Table 4.3 Distribution of Hours and Days, United States, 1977 (\% Distributions) ${ }^{2}$

\begin{tabular}{|c|c|c|c|c|}
\hline \multirow[b]{2}{*}{ Hours } & \multicolumn{4}{|c|}{ Days } \\
\hline & $1-4$ & 5 & $6-7$ & All Days \\
\hline \multicolumn{5}{|c|}{ All Workers ${ }^{b}$} \\
\hline $10-30$ & 2.6 & 5.7 & 1.3 & 9.6 \\
\hline $30.1-39$ & 0.6 & 17.1 & 0.7 & 18.4 \\
\hline $39.1-40$ & 0.8 & 30.7 & 0.8 & 32.3 \\
\hline $40.1-47$ & 0.4 & 13.4 & 2.3 & 16.1 \\
\hline$>47$ & 0.0 & 14.0 & 10.0 & 24.0 \\
\hline All Hours & 4.3 & 81.0 & 15.1 & \\
\hline \multicolumn{5}{|c|}{ Salaried Workers ${ }^{c}$} \\
\hline $10-30$ & 1.4 & 4.1 & 1.0 & 6.5 \\
\hline $30.1-39$ & 0.4 & 21.2 & 0.4 & 22.0 \\
\hline $39.1-40$ & 1.0 & 25.8 & 0.6 & 27.4 \\
\hline $40.1-47$ & 0.2 & 16.4 & 1.0 & 17.6 \\
\hline$>47$ & 0.0 & 18.7 & 7.9 & 26.6 \\
\hline All Hours & 3.0 & 86.2 & 10.9 & \\
\hline \multicolumn{5}{|c|}{ Hourly Paid Workers ${ }^{d}$} \\
\hline $10-30$ & 3.0 & 7.8 & 1.7 & 12.5 \\
\hline $30.1-39$ & 0.8 & 13.6 & 1.0 & 15.4 \\
\hline $39.1-40$ & 0.6 & 36.4 & 1.0 & 38.0 \\
\hline $40.1-47$ & 0.6 & 11.1 & 3.2 & 14.9 \\
\hline$>47$ & 0.0 & 8.6 & 10.7 & 19.3 \\
\hline All Hours & 5.0 & 77.5 & 17.6 & \\
\hline
\end{tabular}

Source. Calculated from the Quality of Employment Survey, 1977

Notes.

${ }^{2}$ Totals do not add to 100 percent because of rounding.

${ }^{b} \mathrm{~N}=1,097$

' $N=507$

${ }^{\mathrm{d}} \mathrm{N}=524$ 
DANIEL S. HAMERMESH

Table 4.4 Distribution of Hours and Days, FRG, 1990, (\% Distributions)

\begin{tabular}{|c|c|c|c|c|}
\hline \multirow[b]{2}{*}{ Hours } & \multicolumn{4}{|c|}{ Days } \\
\hline & $1-4$ & 5 & $6-7$ & All Days \\
\hline \multicolumn{5}{|c|}{ All Workers ${ }^{b}$} \\
\hline $10-30$ & 2.5 & 8.0 & 1.2 & 11.7 \\
\hline $30.1-39$ & 0.6 & 32.6 & 1.5 & 34.7 \\
\hline $39.1-40$ & 0.2 & 20.4 & 1.6 & 22.2 \\
\hline $40.1-47$ & 0.1 & 17.7 & 2.3 & 20.1 \\
\hline$>47$ & 0.1 & 7.6 & 3.6 & 11.3 \\
\hline All Hours & 3.5 & 86.3 & 10.2 & \\
\hline \multicolumn{5}{|c|}{ Salaried Workers ${ }^{c}$} \\
\hline $10-30$ & 4.1 & 10.0 & 1.5 & 15.6 \\
\hline $30.1-39$ & 0.5 & 25.7 & 1.7 & 27.9 \\
\hline $39.1-40$ & 0.1 & 14.7 & 1.7 & 16.5 \\
\hline $40.1-47$ & 0.1 & 22.7 & 2.6 & 25.4 \\
\hline$>47$ & 0.2 & 10.1 & 4.4 & 14.7 \\
\hline All Hours & 5.0 & 83.2 & 11.9 & \\
\hline \multicolumn{5}{|c|}{ Hourly Paid Workers ${ }^{d}$} \\
\hline $10-30$ & 1.2 & 7.2 & 1.1 & 9.5 \\
\hline $30.1-39$ & 0.2 & 37.1 & 1.1 & 38.4 \\
\hline $39.1-40$ & 0.0 & 24.6 & 1.4 & 26.0 \\
\hline $40.1-47$ & 0.0 & 14.6 & 2.1 & 16.7 \\
\hline$>47$ & 0.1 & 6.0 & 3.3 & 9.4 \\
\hline All Hours & 1.5 & 89.5 & 9.0 & \\
\hline
\end{tabular}

Source Calculated from the 1990 Wave (7) of the German Socioeconomic Panel, produced by the Deutsches Institut für Wirtschaftsforschung

Notes.

- Totals do not add to 100 percent because of rounding.

${ }^{\mathrm{b}} \mathrm{N}=4,525$

${ }^{\mathrm{c}} \mathrm{N}=1,978$

$\mathrm{d} N=2,236$

tabulations for the U.S. A somewhat greater percentage (4.3 percent of the total) than in the U.S. works no more than 40 hours per week on 6 or 7 days. This is mainly the reflection of the shorter standard workweek in the FRG. But even workers who are obviously less than full-time constitute about the same percentages (1.3 and 1.2 percent) of the labor force in both countries. Not surprisingly, a smaller proportion (only 0.2 percent) of German workers work long hours on few days than in the U.S.

Clearly, a not insignificant fraction of both the American and the German labor forces works highly unusual schedules, either long hours on few days, or, more commonly relatively short hours over many days per week. This suggests there is a substantial payoff to beginning the investigation of hours/days choices on both 


\section{POLICY TRANSFERABILITY AND HYSTERESIS}

sides of the labor market. That payoff is likely to increase as the importance of goods-producing industries, with their ability to rely on inventories of output and their need for workers' simultaneous presence at a location containing a large capital stock, decreases.

The distribution of hours and days depends, of course, on the interactions among workers' tastes, the daily fixed costs of working that they face, and the nature of the technology that combines days, daily hours and workers. There is unfortunately no direct evidence on employers' and workers' weekly schedules of days and hours. In March 1989, however, the EC conducted surveys of employers and firms in eight countries that enable us to compare employers' and workers' weekly schedules of hours. Table 4.5 shows the results for the FRG. Comparing the data on operating hours (from the employers' survey) and those on contractual hours (from the workers' survey), it seems clear that the distribution of operating hours is shifted far to the right of the distribution of contractual hours. This leaves substantial scope for part-time work, for workers whose weekly schedules in the same job are dovetailed, and for overtime work. The existence of very long operating hours in industry (less so in retail) also demonstrates the scope for and existence of shift work.

Table 4.5 Operating and Contractual Hours, Industry and Retail, FRG, 1989 (\% Distribution)

\begin{tabular}{|c|c|c|c|}
\hline \multicolumn{2}{|c|}{ Operating } & \multicolumn{2}{|c|}{ Contractual } \\
\hline Hours & $\%$ & Hours & $\%$ \\
\hline \multicolumn{4}{|l|}{ Industry } \\
\hline$<40$ & 25 & $<35$ & 0 \\
\hline $40-60$ & 48 & $35-38$ & 56 \\
\hline $60-80$ & 18 & $38-40$ & 43 \\
\hline $80-120$ & 5 & $40-42$ & 1 \\
\hline$>120$ & 2 & $>42$ & 0 \\
\hline (No reply) & 2 & & 0 \\
\hline TOTAL & 100 & & 100 \\
\hline \multicolumn{4}{|l|}{ Retail } \\
\hline$<45$ & 37 & $<35$ & 0 \\
\hline $46-50$ & 27 & $35-38$ & 12 \\
\hline $51-55$ & 16 & $38-40$ & 83 \\
\hline $56-60$ & 4 & $40-42$ & 0 \\
\hline $61-65$ & 10 & $>42$ & 1 \\
\hline $66-75$ & 0 & & \\
\hline$>76$ & 0 & & \\
\hline (No reply) & 6 & & 4 \\
\hline TOTAL & 100 & & 100 \\
\hline
\end{tabular}

Source, European Economy, 1991, Appendix Tables 


\section{EMPLOYMENT-HOURS SUBSTITUTION AND THE EFFECT OF POLICY}

Simply linking differences in the distributions of days and hours to the difference in the structures of hours policies is not very informative. Serious studies of the effects of hours policies on the choice of daily and weekly schedules have not been made even within a country. What we have instead are demand-side studies of the shape of the labor aggregator, $L=L(E, H)$, and studies of the impact of overtime penalties on the choice between workers $E$ and weekly hours $H$. Fortunately, many of these have been based on U.S. and German data, so that we do know a little bit about these issues.

A full treatment is contained in Hamermesh (1993, Chapter 3), but Table 4.6 presents a partial tabular survey of the research that includes all the studies based on the U.S. and the FRG. The German research in the first part of the table presents elasticities of output $Y$ with respect to various inputs of hours and workers, or substitution elasticities between pairs of inputs $H, E$, and capital $K$. The first set of American studies indicates the degree of substitution between part- and full-time workers.

Hart and McGregor (1988) show clearly that the returns to inputs of hours are not increasing. Hart and Kawasaki (1988) measure fixed and variable labor costs more carefully than anyone else. They find that the effects of labor-cost increases on the demand for both workers and hours are more important than any substitution, and that both $E$ and $H$ are p-substitutes for capital. König and Pohlmeier (1988 and 1989) attempt to measure the prices of hours and workers by calculating indexes of overtime premia and various employee benefits. Theirs are the only available studies that provide direct estimates of worker-hours substitution. They imply that workers and hours are p-complements and that they are $p$ substitutes for capital. The results indicate that it may be possible to aggregate workers and hours, but the aggregator is clearly not multiplicative.

Using quite similar methods Owen (1979) finds easy substiturion between the two groups of workers, while Ehrenberg et al. (1988) imply that substitution is much more difficult. Montgomery (1988) presents the most useful results in this group, as his microeconomic data obviate the need to account for the possible endogeneity of supply. His data suggest a small degree of substitution between fulland part-time workers.

The second group of studies estimates equations describing firms' demand for employees and hours. The American research computes the demand for employees as a function of the ratio of the cost of (what the authors believe are) per-worker benefits to the wage rate. All three use waves of the same detailed set of establishment data. The elasticities indicate the percentage change in employment in response to an increase of $1 / 3$ in the price of an hour of overtime (changing the penalty from 50 to 100 percent). They imply that, at a constant input of workerbours, a higher effective per-hour cost imposed by an increased overtime penalty induces some p-substitution from hours to employees. Franz and König (1986) 
POLICY TRANSFERABILITY AND HYSTERESIS

Table 4.6 Studies of Worker-Hour Substitution and the Overtime Penalty

\begin{tabular}{|c|c|c|c|}
\hline Study & Data & Results & \\
\hline $\begin{array}{l}\text { Germany } \\
\text { Hart and } \\
\text { McGregor } \\
(1988)\end{array}$ & $\begin{array}{l}\text { Manufacturing } \\
\text { industries, 1968-1978 }\end{array}$ & $\begin{array}{l}\eta_{Y H}=0.87 \\
\eta_{Y E}=0.30 \\
\eta_{\text {YOvertime }} \approx 0\end{array}$ & \\
\hline $\begin{array}{l}\text { Hart and } \\
\text { Kawasaki } \\
\text { (1988) }\end{array}$ & $\begin{array}{l}\text { Manufacturing, annual, } \\
1951-81\end{array}$ & $\begin{array}{l}\sigma_{E K}, \sigma_{H K}>0 ; \\
\text { scale effects exceed } \\
\text { substitution effects }\end{array}$ & \\
\hline $\begin{array}{l}\text { König and } \\
\text { Pohlmeier } \\
\text { (1988) }\end{array}$ & $\begin{array}{l}\text { Manufacturing, } \\
\text { quarterly, 1969-1985 }\end{array}$ & $\begin{array}{lr}\sigma_{E H}= & -0.16 \\
\sigma_{E K}= & 0.62 \\
\sigma_{H K}= & 0.12\end{array}$ & \\
\hline $\begin{array}{l}\text { König and } \\
\text { Pohlmeier } \\
\text { (1989) }\end{array}$ & $\begin{array}{l}\text { Manufacturing, } \\
\text { quarterly, 1969-1985 }\end{array}$ & $\begin{array}{l}\sigma_{E H}=(-0.40,-0.78) \\
\sigma_{E K}=(1.02,1,41) \\
\sigma_{H K}=(0.72,1.51)\end{array}$ & \\
\hline $\begin{array}{l}\text { Franz and } \\
\text { König (1986) }\end{array}$ & $\begin{array}{l}\text { Manufacturing, quarterly, } \\
\text { 1964-1984. Elasticity } \\
\text { with respect to: }\end{array}$ & $\begin{array}{lc} & H \\
\text { Overtime penalty: } & -0.04 \\
\text { Standard hours: } & 0.99\end{array}$ & $\begin{array}{c}E \\
-0.10 \\
-1.09\end{array}$ \\
\hline \multicolumn{2}{|l|}{ United States } & ${ }^{\sigma}$ Full-time, Part-time & \\
\hline Owen (1979) & $\begin{array}{l}\text { Industries and } \\
\text { occupations, } 1973\end{array}$ & 4.35 & \\
\hline $\begin{array}{l}\text { Ehrenberg } \\
\text { et al (1988) }\end{array}$ & Industries, 1984 & 0.21 & \\
\hline Montgomery (1988) & Plants, 28 cities, 1980 & $\begin{array}{l}0.67 \\
\text { Percent change in } \mathrm{E} \text { given a } \\
\text { one-third increase in the } \\
\text { price of overtime: }\end{array}$ & \\
\hline Ehrenberg (1971) & Manufacturing, 1966 & 1.6 & \\
\hline $\begin{array}{l}\text { Nussbaum and } \\
\text { Wise (1978) }\end{array}$ & Manufacturing, 1966-1974 & 2.0 & \\
\hline $\begin{array}{l}\text { Ehrenberg and } \\
\text { Schumann (1982) }\end{array}$ & $\begin{array}{l}\text { 1976; Manufacturing: } \\
\text { Nonmanufacturing: }\end{array}$ & $\begin{array}{l}(0.5,1.1) \\
(1.0,2.1)\end{array}$ & \\
\hline
\end{tabular}

examine a factor-demand system in which the effect of changing standard weekly hours and raising the overtime penalty can be studied. The interesting result, consistent with Hart and Kawasaki, is that raising the overtime penalty reduces employment (through the scale effect on the demand for worker-hours).

Taken together, if we ignore capital (which the German studies suggest is wrong), this research implies that hours and workers are $p$-substitutes in demand. 
The empirical work is far from extensive enough, though, to allow any conclusions about the strength of this substitution, and thus about the size of the impact of a change in hours laws on employers' relative demand for workers and hours.

\section{CONCLUSIONS, AND THE NEED FOR RESEARCH ON THE HOURS/DAYS DISTINCTION}

In this exploratory study I have demonstrated the difficulties attendant on transferring policies between economies. Even if current labor-market outcomes are identical, a policy that is optimal within one country will be suboptimal within an otherwise identical country unless the two have long identical histories of both policies and outcomes. While the point is not directly testable, I have attempted to illustrate differences in outcomes under currently similar (but not identical) laws regarding overtime.

The genesis of the differences between German and American hours laws and contractual restrictions is beyond the scope of this analysis, and is really an issue in law and economics. How the time paths of these institutional changes have affected patterns of work-days and work-hours is, though, appropriately analyzed using the framework I have developed here. But until we know much more about how patterns of work-days and work-hours differ between the two countries, we cannot answer that comparative question (or even say very much about hours policies within a country). The evidence presented in pages $85-89$ is the first available on this distinction. At this point all we know is that the data, which may not be fully comparable across the two countries, suggest there is more dispersion in weekly hours and in days worked per week in the American than in the German labor force.

To be useful any examination of the threefold distinction in labor input (days, hours and workers) must be based on several countries. This is partly because policies that affect agents' choices differ among countries, so that without accounting for their effects any conclusions based on outcomes in one country are not generalizable. Partly too, underlying patterns of tastes, including those that generate differences in participation, will alter equilibrium hours and days worked. (For example, more two-worker households in one country create more incentives for its retailers to expand opening hours.) These considerations dictate studying these choices in more than one economy.

This modeling and estimation should yield several outcomes:

1 Information on patterns of and differences in days and hours of work in the two countries;

2 Understanding the determinants of these differences in the context of models of employers' and workers' choices among participation (or number of workers), days and hours; and

3 Comparisons of the impacts of international differences in policies and institutions that affect choices about hours and days, and the role of policy hysteresis in generating the time paths of these outcomes. 


\section{ACKNOWLEDGMENTS}

Edward Everett Hale Centennial Professor of Economics, University of TexasAustin, and research associate, National Bureau of Economic Research. I thank the Faculty of Economics of the Rijksuniversiteit Limburg, the Netherlands, for providing the time and facilities to develop these ideas, and Steven Allen, Harry Holzer, Warren Samuels, participants at the Conference sessions, and especially Knut Gerlach for helpful comments. The Deutsches Institut für Wirtschaftsforschung and Syracuse University kindly provided the data for Germany.

\section{NOTES}

1 Among the many recent examples are trans-national comparisons of the U.S. economy and labor market to those of Australia and Sweden (Caves and Krause 1984; Bosworth and Rivlin 1987).

2 This view is embodied in the Webbs' notion of a social minimum wage (Webb and Webb 1920) and still underlies much of the rhetoric about this policy

3 This deterioration is consistent with a variety of evidence on the depreciation of unusued skills, including, e.g., Mincer and Polachek, 1974.

4 The weak inequality becomes strong at all but specific combinations of the $\delta$ and $a_{r}$

5 This representation of the tax/transfer policy is like that in Fair (1971).

6 The productivity shock applies only to Type 1 labor to minimize the notation. The results are qualitatively the same if the shock applies instead to the productivity of Type 2 labor or to both groups' productivity.

7 The only difference in (5) is the addition of terms in $F\left(L_{1, t+i}, L_{2, t+i}\right), i=1, \ldots N$, in the numerator of the right-hand side.

8 If we assume a steady rate of depreciation of the externality rather than the one-hoss shay depreciation in the model, the probability that $H_{t+1}=H_{t}$ becomes very small.

9 Erdmann (1957); U.S. Congress, Office of Technology Assessment, Biological Rhythms, 1991, Table A-1.

10 The sources are Employment and Earnings, June 1970, June 1990; Statistiches Jahrbuch für die Bundesrepublik Deutschland, 1970, 1989; and Eurostat, Labour Force Survey, Results 1989.

11 The 66 workers included in the total but not in either of the two categories list themselves as paid by other methods, e.g., commission, piece rate, daily, etc.

\section{REFERENCES}

Blanchard, O. and Summers, L. (1986) "Hysteresis and the European Unemployment Problem," NBER Macroeconomics Annual.

Blyton, P. (1985) Changes in Working Time, New York: St. Martin's.

Bosworth, B. and Rivlin, A. (1987) The Swedish Economy Washington: Brookings Institution.

Bound, J. and Johnson, G. (1992) "Changes in the Structure of Wages during the 1980's: An Evaluation of Alternative Explanations," American Economic Review 82: 371-392.

Caves, R. and Krause, L. (1984) The Australian Economy: $A$ View from the North, Washington: Brookings Institution.

Ehrenberg, R. (1971) "The Impact of the Overtime Premium on Employment and Hours in U.S. Industry," Economic Inquiry 9: 199-207. 
Ehrenberg, R., Rosenberg, P. and Li, J. (1988) "Part-time Employment in the United States," in Robert Hart (ed.), Employment, Unemployment and Labor Utilization, Boston: Unwin Hyman.

Ehrenberg, R. and Schumann, P. (1982) Longer Hours or More Jobs? Ithaca, NY: Cornell University Press.

Erdmann, G. (1957) Die Entwicklung der deutschen Sozialgesetzgebung. Göttingen: Musterschmidt.

Fair, R. (1971) "The Optimal Distribution of Income," Quarterly Journal of Economics 85: 551-579.

Franz, W. (1987) "Hysteresis, Persistence, and the NAIRU: An Empirical Analysis for the Federal Republic of Germany," in R. Layard and L. Calmfors (eds), The Fight Against Unemployment, Cambridge, MA: MIT Press.

Franz, W. and König, H. (1986) "The Nature and Causes of Unemployment in the Federal Republic of Germany since the 1970's: An Empirical Investigation," Economica 53: S219-S244.

Hamermesh, D. (1993) Labor Demand. Princeton, NJ: Princeton University Press.

Hart, R. and Kawasaki, S. (1988) "Payroll Taxes and Factor Demand," Research in Labor Economics 9: 257-285.

Hart, R. and McGregor, P. (1988) "The Returns to Labour Services in West German Manufacturing Industry," European Economic Review 32: 947-963.

König, H. and Pohlmeier, W. (1988) "Employment, Labor Utilization and Procyclical Labor Productivity," Kyklos 41: 551-572.

- (1989) "Worksharing and Factor Prices: A Comparison of Three Flexible Functional Forms for Nonlinear Cost Schemes," Journal of Institutional and Theoretical Economics 145: 343-357.

Meyer, R. and Wise, D. (1983) "The Effects of the Minimum Wage on the Employment and Earnings of Youth," Journal of Labor Economics 1: 66-100.

Mincer, J. and Polachek, S. (1974) "Family Investments in Human Capital: Earnings of Women," Journal of Political Economy 82: S76-S108.

Montgomery, M. (1988) "On the Determinants of Employer Demand for Part-time Wolkers," Review of Economics and Statistics 70: 112-117.

Nussbaum, J. and Wise, D. (1977) "The Employment Impact of the Overtime Provisions of the FLSA," Final Report, U.S. Department of Labor, 1977.

Owen, J. (1979) Working Hours, Lexington, MA: D.C. Heath. (1989) Reduced Working Hours, Baltimore: Johns Hopkins.

Pack, H. (1988) "Industrialization and Trade," in H. Chenery and T. N. Srinivasan (eds), Handbook of Development Economics, Vol. 1, Amsterdam: North-Holland.

Stigler, G. and Becker, G. (1977) "De Gustibus Non Est Disputandum," American Economic Review 67: 76-90.

Webb, S. and Webb, B. (1920) Industrial Democracy, London: Longmans Green. 